\title{
Possible Relationship of Weakened Aleutian Low with Air Quality Improvement in Seoul, South Korea ${ }^{\mathscr{O}}$
}

\author{
Hye-Ryun OH AND CHANG-HoI Ho \\ School of Earth and Environmental Sciences, Seoul National University, Seoul, South Korea \\ DOO-SUN R. PARK \\ Department of Earth Sciences, Chosun University, Gwangju, South Korea \\ JINWON KIM \\ Department of Atmospheric and Oceanic Sciences, University of California, Los Angeles, Los Angeles, California \\ Chang-Keun SONG \\ Air Quality Research Division, National Institute of Environment Research, Incheon, and School of Urban and Environmental \\ Engineering, Ulsan National Institute of Science and Technology, Ulsan, South Korea \\ SUN-KYONG HUR \\ School of Earth and Environmental Sciences, Seoul National University, Seoul, South Korea
}

(Manuscript received 23 October 2017, in final form 4 July 2018)

\begin{abstract}
Cold-season air quality in Seoul, South Korea, has been improved noticeably between 2001 and 2015 with a near-50\% decrease in the mean concentration of particulate matter with aerodynamic diameters $\leq 10 \mu \mathrm{m}$ $\left(\mathrm{PM}_{10}\right)$. Like the change in mean concentration, the occurrence frequency and intensity of the extreme-high$\mathrm{PM}_{10}$ episodes exceeding $100 \mu \mathrm{g} \mathrm{m}^{-3}$ has significantly decreased as well. In addition to the multilateral efforts of the South Korean government to reduce air pollutant emissions, this study proposes that large-scale circulation changes also could have contributed to the air quality improvements. Specifically, the recent weakening of the Aleutian low may have intensified the tropospheric westerlies around the Korean Peninsula, resulting in a shorter residence time of particulate matter over South Korea. Thus, despite constant governmental effort to reduce pollutant emissions, the improvement in air quality over South Korea may be delayed if the Aleutian low recovers its past strength in the future. This study emphasizes the importance of the meteorological field in determining the air quality over South Korea.
\end{abstract}

\section{Introduction}

Air pollution is known to cause numerous adverse social and economic issues, such as reduction of visibility, mechanical failure in facilities, and deterioration of plant growth (Harrison and Yin 2000; Hong et al. 2002; Lau

Supplemental information related to this paper is available at the Journals Online website: https://doi.org/10.1175/JAMC-D-170308.s1.

Corresponding author: Chang-Hoi Ho, hoch@cpl.snu.ac.kr et al. 2008; Hyslop 2009). The adverse effects of air pollution on human health are among the most serious concerns (Pope and Dockery 2006). Worldwide, approximately 800000 premature deaths occur each year due to particulate matter (PM) air pollution, making it the thirteenth leading cause of mortality (Anderson et al. 2012). Several epidemiological studies have shown a consistent increase in cardiac and respiratory morbidity and mortality from exposure to PM (Pope and Dockery 2006): a $10 \mu \mathrm{g} \mathrm{m}^{-3}$ increase in the average 24-h PM with aerodynamic diameters $\leq 10 \mu \mathrm{m}\left(\mathrm{PM}_{10}\right)$ concentration is associated with an increase in daily mortality of 
approximately $0.6 \%$ (Samoli et al. 2008). Therefore, the World Health Organization (WHO) has set guidelines for $\mathrm{PM}_{10}$, urging that its annual and 24-h average concentrations should be less than $20 \mu \mathrm{g} \mathrm{m}^{-3}$ and $50 \mu \mathrm{g} \mathrm{m}^{-3}$, respectively (WHO 2006, 174-175).

Accordingly, developed countries have attempted to control pollutant emissions by promoting public transportation, clean burning, renewable fuels, and energy efficient plants and buildings (WHO 2006, 174-175). For example, in the states of the European Union (EU), the number of high- $\mathrm{PM}_{10}$ days, that is, a 24-h average $\mathrm{PM}_{10}$ concentration larger than $50 \mu \mathrm{g} \mathrm{m}^{-3}$, is not supposed to exceed a frequency of 35 days $\mathrm{yr}^{-1}$ (Ştefan and Roman 2015). In case a member state exceeds the limit, it has to report and explain the exceedance frequency. In 2005, the South Korean government began to implement the 10-Year Act, including a series of strict policies to reduce the local emission of air pollutants in major cities (e.g., Seoul, Pusan, Daegu, Daejeon, and Gwangju), where more than half of the population of South Korea resides (Baek and Koo 2008; Gyeonggi Research Institute 2011). The government invested approximately 4 trillion South Korean won ${ }^{1}$ in the act for the first 10 years. The second phase of the 10-Year Act commenced in 2015 (http://eng.me.go.kr/eng/web/ index.do?menuId=238). It includes various air quality control strategies, such as enforcing the installation of particulate filters in diesel engines, encouraging the use of eco-friendly (i.e., hybrid and electric) cars, and increasing air pollutant monitoring (Gyeonggi Research Institute 2011; Kamal-Chaoui et al. 2011; Kim and Shon 2011).

Previous studies have reported that $\mathrm{PM}_{10}$ concentrations in Seoul have steadily decreased over the past few years because of the various policies implemented to improve air quality (e.g., Lee et al. 2011; Ahmed et al. 2015). However, ambient $\mathrm{PM}_{10}$ concentration levels can also be significantly influenced by the tropospheric circulation (Zhang et al. 2009; Gao et al. 2011; Titos et al. 2014). For example, the presence of a strong anticyclonic pattern leads to a stable meteorological condition, typically characterized by warmer temperature, stagnant winds, and lower mixing depth, which tends to increase the local $\mathrm{PM}_{10}$ levels (Pun and Seigneur 1999; Grambsch 2009). A nearly stationary large-scale meteorological pattern, known as blocking, can cause high- $\mathrm{PM}_{10}$-concentration episodes by preventing the dispersion of air pollutants (Lee et al. 2013; Seo et al. 2017). The $\mathrm{PM}_{10}$ concentration in South Korea has also been found to be highly

\footnotetext{
${ }^{1}$ In July 2018, \$1 corresponded to 1,115 KRW.
}

influenced by the tropospheric wind speed over the country (Kim et al. 2017).

Because of the importance of the meteorological circulation of air quality, this study aims to investigate if there is any evidence to suggest that changes in tropospheric circulation could have contributed to the recent improvements in air quality in South Korea, along with the government's actions on emission control.

\section{Data and methods}

We utilized the hourly $\mathrm{PM}_{10}$ mass concentration, measured at 27 air quality monitoring sites in Seoul, during the cold season (October-March) of 2001-15. Since 2 of the sites were closed in 2009, the data from the remaining 25 sites were utilized for 2009-15. Considering that Seoul has the longest and the most qualified $\mathrm{PM}_{10}$ concentration data, we utilized the $\mathrm{PM}_{10}$ concentration of Seoul as a representative value for South Korea (http://www.airkorea.or.kr/detailViewDown). For comparison, the $\mathrm{PM}_{10}$ concentration data of six other major cities (i.e., Pusan, Daejeon, Daegu, Gwangju, Incheon, and Ulsan) were examined. The number of monitoring sites in the 6 cities is less than that in Seoul (http://www.airkorea.or.kr/detailViewDown): 10 in Pusan, 4 in Daejeon, 7 in Daegu, 5 in Gwangju, 11 in Incheon, and 13 in Ulsan. The $\mathrm{PM}_{10}$ concentration data were measured using the beta-ray absorption method, which determines the concentration by detecting the attenuation that occurs when beta rays irradiate particulate matter collected on a filter (Shin et al. 2011). The measurement error, mainly due to particlecontaining moisture, is known to be $10 \%$ (Chang and Tsai 2003).

In this study, the collected hourly data were converted into daily average values. We analyzed high- $\mathrm{PM}_{10}$ episodes to explain the overall change in $\mathrm{PM}_{10}$ air quality in Seoul. High- $\mathrm{PM}_{10}$ episodes are defined as events in which the daily mean $\mathrm{PM}_{10}$ concentration exceeds $100 \mu \mathrm{g} \mathrm{m}^{-3}$, in accordance with Lee et al. (2011) and Oh et al. (2015). Since high- $\mathrm{PM}_{10}$ episodes over South Korea can occur because of both anthropogenic sources and yellow dust events (Koo et al. 2010; Lee et al. 2011), it is necessary to classify each episode based on its cause (Shin et al. 2007). Here, we focus only on anthropogenic high- $\mathrm{PM}_{10}$ episodes. Therefore, 62 yellow dust days issued by the Korea Meteorological Administration (KMA; http://web.kma. go.kr/eng/weather/asiandust/intro.jsp) were excluded from the overlapping high- $\mathrm{PM}_{10}$ episodes. A total of 108 episodes (217 days) during the analysis period were selected as the anthropogenic high- $\mathrm{PM}_{10}$ episodes. To determine whether the high-PM $\mathrm{PM}_{10}$ days in Seoul are representative of the nationwide air quality, we used the 
ratio of small mode aerosol optical depth (AOD) to the total AOD at $0.55 \mu \mathrm{m}$, which is called the fine mode fraction (FMF), obtained from Moderate Resolution Imaging Spectroradiometer (MODIS)/Terra (Levy et al. 2013; https://ladsweb.modaps.eosdis.nasa.gov/search/order). This was because the anthropogenic AOD is dominated by small mode aerosols. Because of cloud contamination, some of the high- $\mathrm{PM}_{10}$ days could not be checked. Therefore, we were able to examine 173 days out of a total of 217 high- $\mathrm{PM}_{10}$ days.

To evaluate meteorological contributions to the recent improvements in the $\mathrm{PM}_{10}$ air quality, daily meteorological data, including geopotential height and zonal and meridional wind at the $500-\mathrm{hPa}$ level, were obtained from the National Centers for Environmental Prediction-National Center for Atmospheric Research (NCEP-NCAR) Reanalysis 2, with a longitude-latitude resolution of $2.5^{\circ} \times 2.5^{\circ}$ (Kalnay et al. 1996). We used anomalies against the daily climatology for 2001-15 to exclude seasonality while identifying the meteorological characteristics on high- $\mathrm{PM}_{10}$ days. The daily precipitation and wind speed, observed at the weather stations of Seoul, were obtained from the KMA (http:// www.kma.go.kr). All meteorological data were analyzed for the same period as that of the $\mathrm{PM}_{10}$ concentration data used.

We further used the total amount of emissions for 2001-14 to examine the relative contributions from large-scale circulations, precipitation frequency, and local emissions to the $\mathrm{PM}_{10}$ level over South Korea using data from the National Air Pollutants Emission Service (http:// airemiss.nier.go.kr/mbshome/mbs/airemiss/index.do).

\section{Results}

Figure 1a displays the time series of the number of the mean $\mathrm{PM}_{10}$ concentration (black filled circles), high-PM $\mathrm{PM}_{10}$ days (gray filled circles), and the intensity of high- $\mathrm{PM}_{10}$ episodes (gray open circles) during the cold seasons of 2001-14. There is a notable downward trend in both the cold-season-mean $\mathrm{PM}_{10}$ concentration and high- $\mathrm{PM}_{10}$ days. During the analysis period, the number of the cold-season-mean $\mathrm{PM}_{10}$ level and high- $\mathrm{PM}_{10}$ days decreased by $22 \mu \mathrm{g} \mathrm{m}^{-3}$ decade $^{-1}$ and 19 days decade ${ }^{-1}$, respectively. Both the trends are statistically significant at the $99 \%$ confidence level. The intensity of high- $\mathrm{PM}_{10}$ episodes, defined as the $\mathrm{PM}_{10}$ concentration on the day of the onset of high- $\mathrm{PM}_{10}$ episodes, also declined significantly by $9.8 \mu \mathrm{g} \mathrm{m}^{-3} \mathrm{decade}^{-1}$. Figure $1 \mathrm{~b}$ shows the trend of probability distribution functions of daily mean $\mathrm{PM}_{10}$ concentrations during the analysis period. The trend is positive for low $\mathrm{PM}_{10}$ concentration $\left(\leq 50 \mu \mathrm{g} \mathrm{m}^{-3}\right)$, while it is negative for most
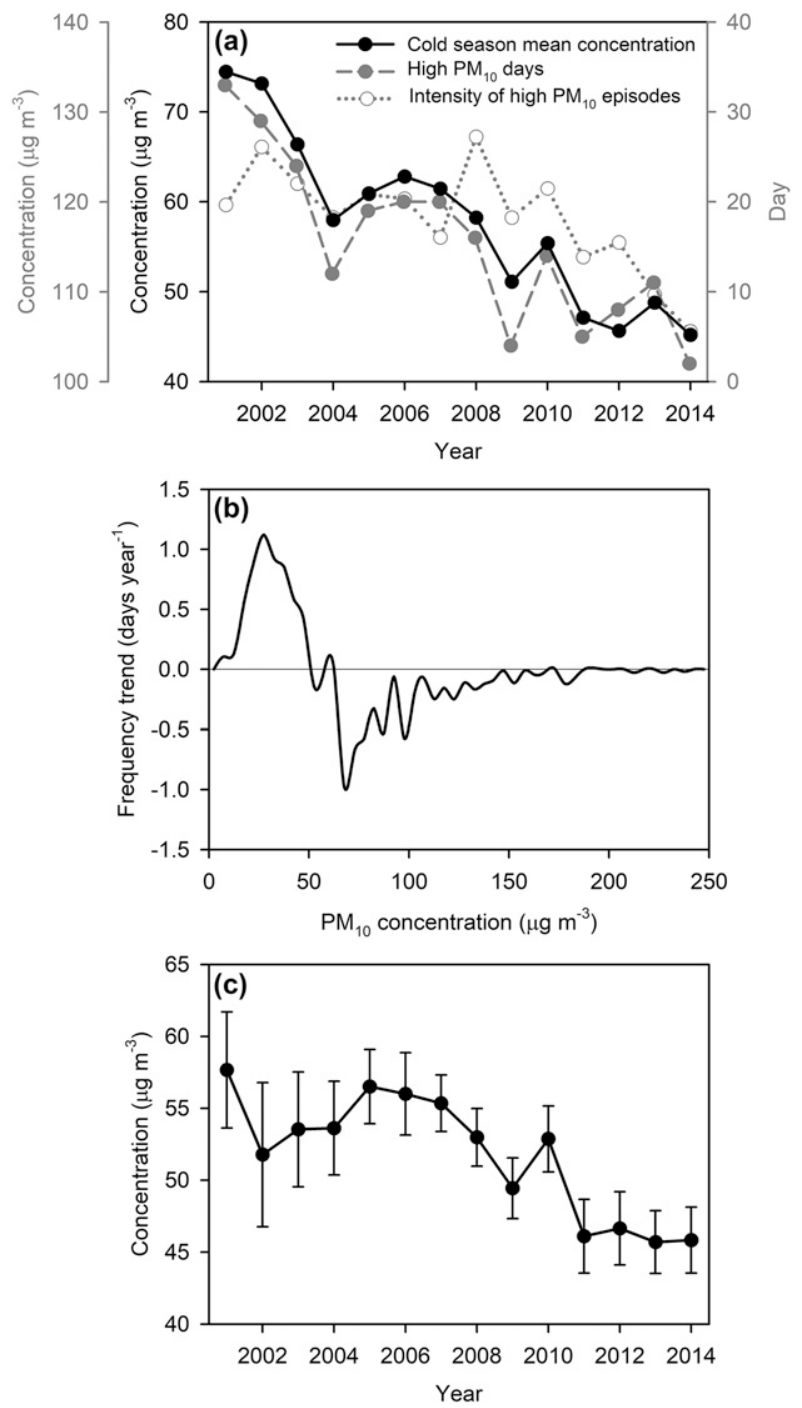

FIG. 1. (a) Average $\mathrm{PM}_{10}$ concentration (black filled circles), high- $\mathrm{PM}_{10}$ days $\left(>100 \mu \mathrm{g} \mathrm{m}^{-3} \mathrm{day}^{-1}\right.$; gray filled circles), and intensity of high- $\mathrm{PM}_{10}$ episodes (gray open circles) during the cold season in Seoul; (b) the trend of probability distribution functions of daily mean $\mathrm{PM}_{10}$ concentrations; and (c) average $\mathrm{PM}_{10}$ concentration (black circles) in the six major cities (Pusan, Daejeon, Daegu, Gwangju, Incheon, and Ulsan) of South Korea. The years along the $x$ axis represent the starting year of each cold season (e.g., the year 2014 means October 2014-March 2015).

moderate and high $\mathrm{PM}_{10}$ concentrations. The result indicates that low-concentration days have become more frequent in recent years, and vice versa.

Here, to see if the $\mathrm{PM}_{10}$ concentration of Seoul is representative of the air quality of South Korea as a whole, we examined the $\mathrm{PM}_{10}$ concentration in six major cities in South Korea (i.e., Pusan, Daejeon, Daegu, Gwangju, Incheon, and Ulsan). Figure 1c shows the coldseason-mean $\mathrm{PM}_{10}$ concentrations (black circles) of the 

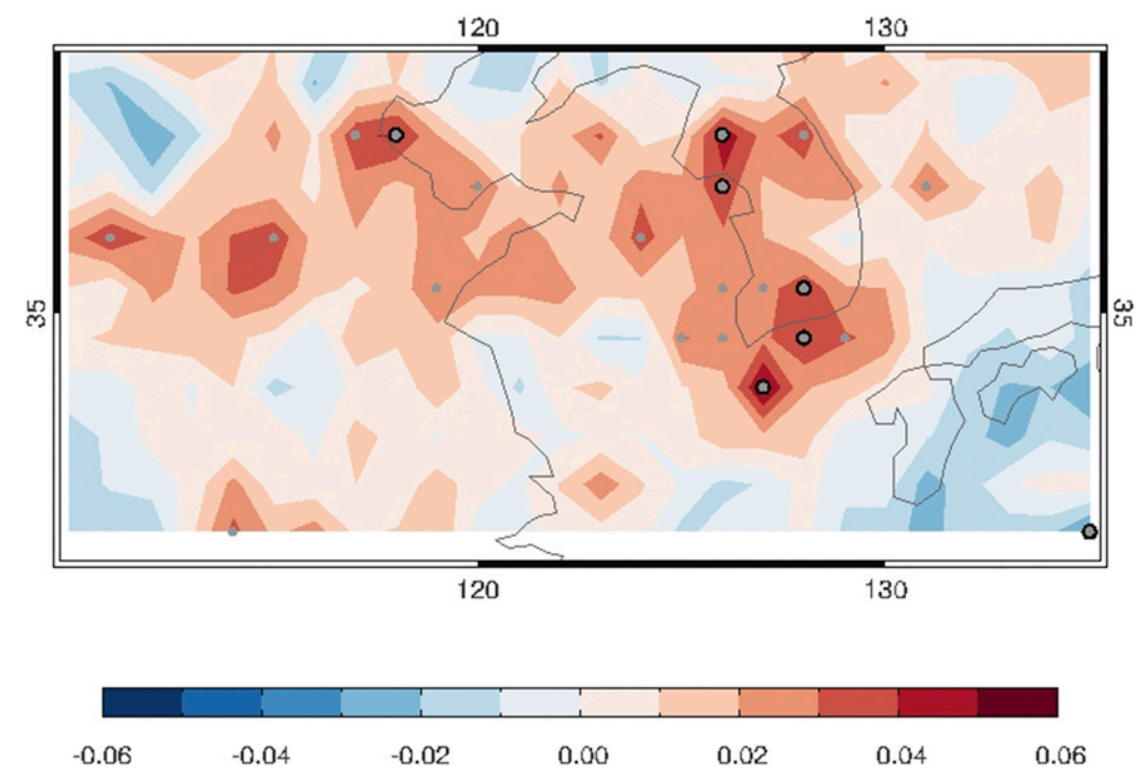

FIG. 2. Composites of anomalous FMF for the high- $\mathrm{PM}_{10}$ day in Seoul from MODIS/Terra. FMF is the ratio of small mode AOD to the total AOD at $0.55 \mu \mathrm{m}$. Gray and black dots denote the regions significant at the $90 \%$ and $95 \%$ confidence levels based on the $t$ test, respectively.

six cities. In accordance with the trend for Seoul (Fig. 1a), the long-term trends were downward. The number of cold-season-mean $\mathrm{PM}_{10}$ levels decreased by $8 \mu \mathrm{g} \mathrm{m}^{-3}$ decade $^{-1}$ during the analysis period. Although the trend is smaller than those in Seoul, a notable trend is observed in the five other cities (not shown). There are significant correlations in the $\mathrm{PM}_{10}$ concentrations of Seoul with those of the other cities (correlation coefficient $r$ within the range of $0.60-0.91$, being 0.73 on average) as well, which means that the $\mathrm{PM}_{10}$ concentration of Seoul can represent general air quality in South Korea. This is also consistent with the satellite data analysis results (Fig. 2): positive FMF anomalies in South Korea and northeastern China for high- $\mathrm{PM}_{10}$ days in Seoul. This indicates that small-sized particles increased across a vast area, including northeastern China and South Korea, during the high- $\mathrm{PM}_{10}$ days in Seoul. These results suggest that $\mathrm{PM}_{10}$ concentration in Seoul adequately reflects the $\mathrm{PM}_{10}$ level across the entire country. Hence, hereafter, we will utilize only Seoul's $\mathrm{PM}_{10}$ concentration data, which are of good quality with regard to the observation in the country, as mentioned in the data and methods section.

To understand the causes of the change in air quality over the large area of South Korea from the perspective of large-scale circulation, we first analyzed the time evolution of geopotential heights for high- $\mathrm{PM}_{10}$ episodes. The geopotential heights are plotted from lag day -3 to lag day +3 from the onset day of the high $\mathrm{PM}_{10}$ episodes (Fig. 3). The typical synoptic weather pattern to cause high- $\mathrm{PM}_{10}$ episodes is the stagnant high pressure system over the Korean Peninsula. During the high-PM $\mathrm{PM}_{10}$ episodes, weather systems move slowly during the entire lag-day period. There is the dominant pattern that a strong anomalous high is located over South Korea, accompanied by an anomalously deep low over the Bering Sea. Considering that the typical geopotential height pattern over East Asia and the North Pacific that is characterized by the west high (Siberian high) and east low (Aleutian low) pressure during the cold season (Rodionov et al. 2005), the large-scale circulation for high- $\mathrm{PM}_{10}$ episodes indicates a strong wavy pattern of the annual-mean geopotential height. The synoptic weather systems generally move slowly, because the quasi-stationary large and deep structures, such as the Aleutian low, can slow down the weather systems moving to its east, and vice versa. The negative pressure anomaly over the Bering Sea could obstruct the eastward movement of the anomalous high over South Korea. The low over the Bering Sea deepens further through lag days -3 to -1 , so that it can effectively inhibit the eastward propagation of the high over the north of South Korea, as shown as in lag day -3 (Fig. 3). In fact, from lag day -3 to lag day 0 , the high moved slowly southeastward instead of eastward. Consequently, the stagnant high could lead to more stable, less windy, and dry tropospheric conditions, all of which are favorable for the occurrence of high $\mathrm{PM}_{10}$ (Lee et al. 2011). After lag day 0 , the deepened low over the Bering Sea begins to decay (Figs. 3d-f). At the same time, the high over 

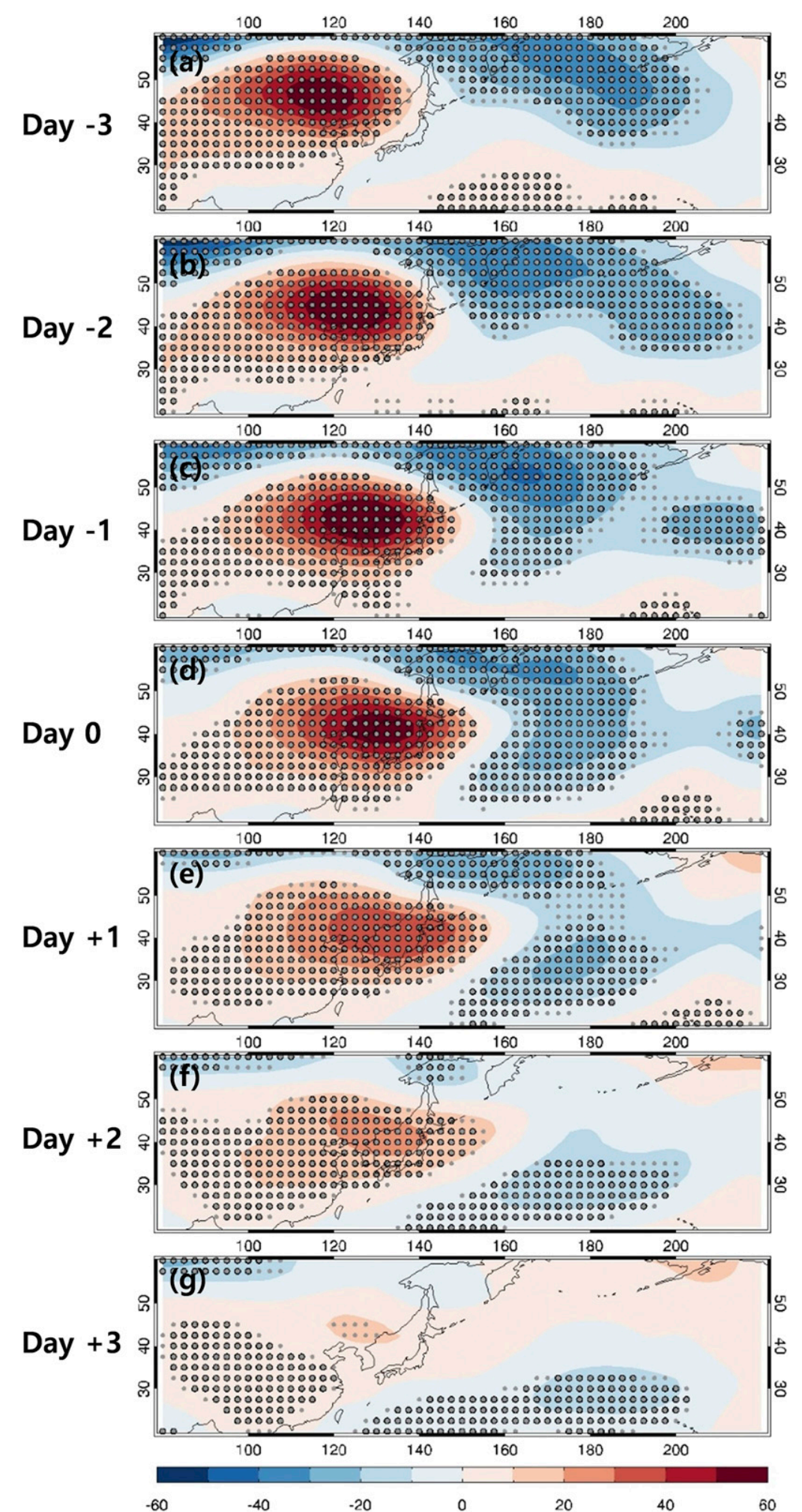

FIG. 3. Composite of anomalous geopotential height at $500 \mathrm{hPa}$ from lag day -3 to lag day +3 from the day of onset of the high- $\mathrm{PM}_{10}$ episodes. Gray and black dots denote the regions significant at the $90 \%$ and $95 \%$ confidence levels based on the Student's $t$ test, respectively. 
South Korea moves rapidly toward the east, finally dissipating on lag day +3 . Thus, the standing low over the Bering Sea can be considered as the main trigger for the high- $\mathrm{PM}_{10}$ episodes, while its intensity can be an important precursor for the persistence of the high- $\mathrm{PM}_{10}$ episodes.

Figure 3 suggests that the tropospheric large-scale circulation may have affected high $\mathrm{PM}_{10}$ episodes. To examine the relationship between high- $\mathrm{PM}_{10}$ episodes and large-scale circulations, we identified the days that have an atmospheric circulation pattern identical to the high$\mathrm{PM}_{10}$ episodes, while not considering the $\mathrm{PM}_{10}$ concentrations. The days are defined as "similar-pattern days with high- $\mathrm{PM}_{10}$ days," when correlations in their patterns of $500-\mathrm{hPa}$ geopotential heights with the day-0 geopotential height (i.e., the anomalous anticyclonic circulation over East Asia and cyclonic circulation over the Northwest Pacific), as shown in Fig. 3d, are higher than 0.4 over East Asia and the Northwest Pacific $\left(30^{\circ}-55^{\circ} \mathrm{N}\right.$, $100^{\circ}-175^{\circ} \mathrm{E}$ ). Note that the threshold value, 0.4 , is not only statistically significant at the $99 \%$ confidence level but also the highest to get a sufficient number of similarpattern days (i.e., about 40 days). If we apply a higher threshold value, the number of similar-pattern days decreases. Conversely, if we apply a lower one, the statistical significance becomes worse. The similar-pattern days have significantly decreased by 15 days decade ${ }^{-1}$ (Fig. 4a), indicating less favorable large-scale conditions for the occurrence of high- $\mathrm{PM}_{10}$ episodes. This further implies that the changes in large-scale circulation may have contributed to the recent reduction in the $\mathrm{PM}_{10}$ concentration over South Korea (Fig. 1a). The correlation coefficient between similar-pattern days and the cold-season-mean $\mathrm{PM}_{10}$ concentration is 0.56 , which is statistically significant at the $95 \%$ confidence level. It is noted that the similar-pattern days are not always related to high- $\mathrm{PM}_{10}$ episodes; the number of picked similarpattern days is larger (approximately 40 days) than that of the high- $\mathrm{PM}_{10}$ days (approximately 20 days). This indicates other factors also play important roles in determining air quality.

The very well-known primary factors to determine the ambient $\mathrm{PM}_{10}$ level are the amount of emission and precipitation (Gao et al. 2011). Emission is the main source of tropospheric $\mathrm{PM}_{10}$, while rainfall is the major sink because of its wet scavenging effect (Loosmore and Cederwall 2004; Choi et al. 2008; Kim et al. 2014). Therefore, we investigated these two key factors, that is, emission amount of $\mathrm{PM}_{10}$ in Seoul (Fig. 4b) and frequency of light and moderate-to-heavy rainfall (Fig. 4c) in addition to the similar-pattern days.

It should be noted that the method for estimating emissions in South Korea has been changed almost
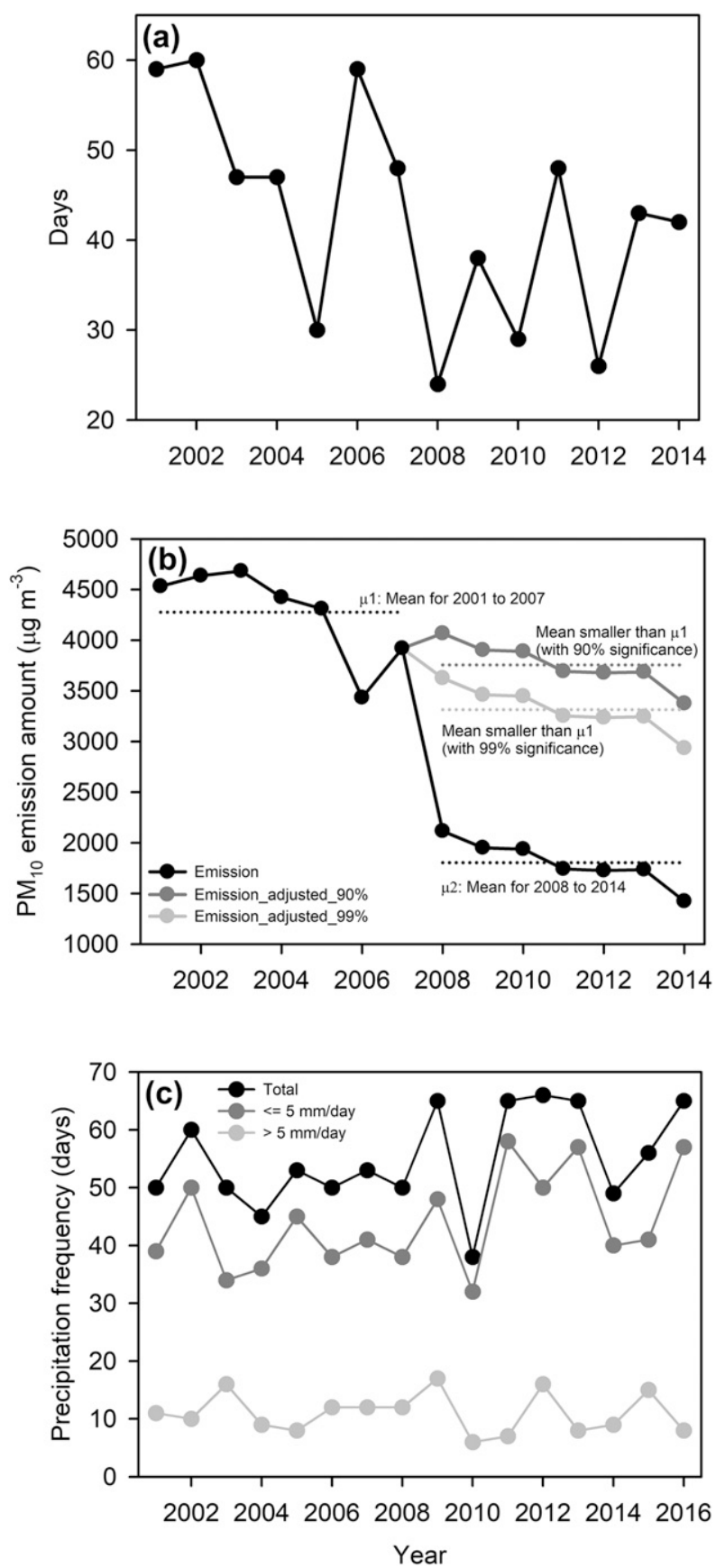

FIG. 4. (a) Time series of similar-pattern days with high-PM $\mathrm{PM}_{10}$ episodes when the pattern correlation coefficient of anomalous geopotential height at $500 \mathrm{hPa}$ vs Fig. $3 \mathrm{~d}$ is higher than 0.4 over the region of $30^{\circ}-55^{\circ} \mathrm{N}, 100^{\circ}-175^{\circ} \mathrm{E}$; (b) annual-average emission amount of $\mathrm{PM}_{10}$ and emission amount for 2008-14 adjusted to have average difference from 2001 to 2007 with exactly $90 \%$ and 99\% significance; and (c) frequency of total (black circles), moderate-to-heavy (dark gray circles), and light (gray circles) precipitation during the cold season in Seoul. The emission data are available from the National Air Pollutants Emission Service (http://airemiss.nier.go.kr/mbshome/mbs/airemiss/index.do). 
every year. In particular, an abrupt drop of emissions in Seoul occurred in 2008 (Fig. 4b), which would be due to the alteration in the classification system of roadmovement pollution sources and the method for estimating them (D. Kim et al. 2010). This change especially contaminates emissions data for megacities like Seoul that cope with heavy vehicular traffic. The big drop shown in Seoul is not observed in other small cities and rural areas (not shown). Therefore, we attempted to adjust the emissions data across the years 2007 and 2008. Let $\mu 1$ and $\mu 2$ (black dotted lines) stand for the mean emissions for two periods $2001-07$ and $2008-14$, respectively, from the original emissions record (black line in Fig. 4b). We reproduced two new time series (dark and light gray lines in Fig. 4b) by letting the difference between $\mu 1$ and $\mu 2$ become statistically significant at the $90 \%$ (90\%-drop time series) and 99\% (99\%-drop time series) confidence levels, respectively. In other words, we left only significant changes at the $90 \%$ and $99 \%$ confidence levels. On the other hand, there was a major change in the estimation method on emission in 2007; that is to say, the fugitive dust and anthracite are additionally taken into account. As a result, the estimated emission largely increased between 2007 and 2008, particularly in nonurban areas in which many power plants are located (not shown). Our analysis, however, can be regarded as investigations on pure urban areas, since we examined the $\mathrm{PM}_{10}$ levels of Seoul, which is a megacity with about 10 million people. In addition, the urban $\mathrm{PM}_{10}$ levels can be less influenced by nonurban sources. Considering these two points, we could ignore this inconsistency problem between 2007 and 2008 . Actually, there was little change in Seoul's emission data between the years (see Fig. 4b).

There are strong negative trends in the original emission data $\left(-298.5 \mu \mathrm{g} \mathrm{m}^{-3} \mathrm{yr}^{-1}\right)$, as well as in the revised data at the $90 \%\left(-88.3 \mu \mathrm{g} \mathrm{m}^{-3} \mathrm{yr}^{-1}\right)$ and the $99 \%$ $\left(-135.8 \mu \mathrm{g} \mathrm{m}^{-3} \mathrm{yr}^{-1}\right)$ confidence level. Despite the uncertainty in the emission data, the correlation coefficient between the cold-season-mean $\mathrm{PM}_{10}$ level (intensity of high- $\mathrm{PM}_{10}$ episode) and the emissions profiles is in the range of approximately $0.76-0.88(0.52-0.64)$. This indicates that a significant portion of the decreased $\mathrm{PM}_{10}$ level in Seoul is affected by the reduced local emissions due to the successful government policy (e.g., a wide use of natural gas busses and introduction of the tenth-dayno-driving system) for controlling air quality in the metropolitan areas, as previously demonstrated (K.-H. Kim et al. 2010; Kim and Shon 2011).

For rainfall (Fig. 4c), there is a slight positive trend, $0.64 \mathrm{yr}^{-1}$, in the frequency of total precipitation. Particularly, the increasing trend, $0.77 \mathrm{yr}^{-1}$, is dominant in the light rain category below $5 \mathrm{~mm} \mathrm{day}^{-1}$ even if light
TABLE 1. Adjusted coefficients of determination for averaged $\mathrm{PM}_{10}$ concentration during the cold season in Seoul with explanatory variables as $\mathrm{PM}_{10}$ emission amount, adjusted emission with $90 \%$ - and $99 \%$-significant decrease from the year 2008, similarpattern days, and precipitation frequency.

\begin{tabular}{lc}
\hline \hline & $\begin{array}{c}\text { Adjusted coefficients } \\
\text { of determination }\end{array}$ \\
\hline $\begin{array}{l}\text { Emission, similar-pattern days, } \\
\text { precipitation frequency }\end{array}$ & 0.72 \\
Adjusted emission (90\%), similar-pattern & 0.73 \\
$\quad$ days, precipitation frequency & \\
Adjusted emission (99\%), similar-pattern & 0.77 \\
$\quad$ days, precipitation frequency & \\
$\quad$ Emission, similar-pattern days & 0.74 \\
Adjusted emission (90\%), similar-pattern & 0.69 \\
$\quad$ days & \\
Adjusted emission (99\%), similar-pattern & 0.76 \\
$\quad$ days & \\
Emission, precipitation frequency & 0.73 \\
Adjusted emission (90\%), precipitation & 0.55 \\
$\quad$ frequency & \\
Adjusted emission (99\%), precipitation & 0.71 \\
$\quad$ frequency & \\
Similar-pattern days, precipitation & 0.34 \\
$\quad$ frequency & \\
Emission & 0.75 \\
Adjusted emission (90\%) & 0.55 \\
Adjusted emission (99\%) & 0.72 \\
Pimilar-pattern days & \\
\hline Precipitation frequency & \\
\hline
\end{tabular}

rainfall is not a good scavenger of $\mathrm{PM}_{10}$ (Choi et al. 2008). The frequency of moderate-to-heavy rainfalls that efficiently remove tropospheric $\mathrm{PM}_{10}$ has decreased by $-0.13 \mathrm{yr}^{-1}$.

To explain the relative contributions of each factor (i.e., the similar-pattern days, emission, and precipitation frequency) on reducing the $\mathrm{PM}_{10}$ level over South Korea, multiple linear regression analysis was applied. We used similar-pattern days, the total precipitation frequency, and emission as independent variables. We performed the multiple linear regression in various combinations. Table 1 summarizes the adjusted $r^{2}$ value for the mean $\mathrm{PM}_{10}$ concentration during the cold season in Seoul. The result of the multilinear regression using all these variables explains the greatest portion of the change in the cold-season $\mathrm{PM}_{10}$ concentration. Interestingly, the revised emissions profile (Table 1) yields higher $r^{2}$ than the original emissions profile (Table 1), indicating that the revised emissions profile better accounts for the changes in the $\mathrm{PM}_{10}$ concentration. Table 2 shows the regression coefficient and corresponding $p$ values for each predictand. The regression coefficients for the emissions profile and the similar-pattern days are positive, but that for precipitation is negative. This indicates that 
TABLE 2. Multiple-regression result for averaged $\mathrm{PM}_{10}$ concentration during the cold season in Seoul with explanatory variables as $\mathrm{PM}_{10}$ emission amount, adjusted emission with $90 \%$ - and $99 \%$ significant decreases from the year 2008, similar-pattern days, and precipitation frequency.

\begin{tabular}{lcc}
\hline \hline & Regression coefficients & $p$ value \\
\hline Intercept & 43.08 & 0.00 \\
Emission & 0.01 & 0.00 \\
Similar-pattern days & 0.12 & 0.41 \\
Precipitation frequency & -0.13 & 0.47 \\
Intercept & 2.79 & 0.88 \\
Adjusted emission (90\%) & 0.01 & 0.00 \\
Similar-pattern days & 0.33 & 0.02 \\
Precipitation frequency & -0.26 & 0.15 \\
Intercept & 16.03 & 0.26 \\
Adjusted emission (99\%) & 0.01 & 0.00 \\
Similar-pattern days & 0.23 & 0.08 \\
Precipitation frequency & -0.18 & 0.26 \\
\hline
\end{tabular}

our results are reasonable, since more emissions and similar-pattern days increase $\mathrm{PM}_{10}$ level, while more precipitation decreases $\mathrm{PM}_{10}$ level. The similar-pattern days solely explain about $26 \%$ of the variance of the $\mathrm{PM}_{10}$ concentrations, while the emissions profile and precipitation explain about $67 \%$ and $5 \%$ of the variance, respectively.

To find the relationship between change in similarpattern days and large-scale circulation, Fig. 5 depicts the regression map of $500-\mathrm{hPa}$ geopotential height against the time series of similar-pattern days (Fig. 5a) and the trend of 500-hPa geopotential height over the analysis period (Fig. 5b). Figures $5 \mathrm{a}$ and $5 \mathrm{~b}$ represent nearly the same features with opposite signs. This indicates that the large-scale circulation associated with similar-pattern days has a significant relevance to the intensified Aleutian low, while the Aleutian low has recently become weak. The low pressure anomaly over the Bering Sea turned into a high pressure anomaly (Fig. 5b). This change indicates that the trough became relatively shallower, suggesting that the low pressure system was weaker. Particularly, the fact that the significant decrease in $500-\mathrm{hPa}$ geopotential height is only shown over the Aleutian implies that the weakened Aleutian low is considerably related to the recent decrease of synoptic weather patterns of similar-pattern days over South Korea. The correlation coefficient between the similar-pattern days and the geopotential height over the Aleutian low area is 0.69 , implying that the Aleutian low does not account for $100 \%$ of the variation of the similarpattern days although the correlation coefficient is statistically significant at the $99 \%$ confidence level. In fact, Zhang et al. (2008) and Glotfelty et al. (2014) implied a possible role of the Aleutian low in transporting the Asian pollution plume from East Asia to North America across the Pacific by westerly winds. However, the role was just examined as a climatological-mean perspective.

As discussed above, the similar-pattern days can be described as the stagnant high system, hence it may allow air quality to become bad by reducing local wind speed and so vertical mixing. Actually, wind speed in Seoul has become significantly stronger in the recent decades at the 99\% confidence level (Fig. S1 in the online supplementary material). The similar-pattern days and the wind speed are significantly correlated with each other $(r=-0.58)$ as well. Hence, it can be considered that the decreased frequency of occurrence of similar-pattern days, accelerating the tropospheric flows over South Korea, plays a role in improving the air quality in South Korea.

\section{Summary and discussion}

This study shows a sharp decline in the $\mathrm{PM}_{10}$ concentration over South Korea in recent years. Through the multilinear regression analysis, we found that a significant variance (approximately 26\%) with regard to the improved air quality is explained by the changes in the large-scale tropospheric circulations, although a large portion of the air quality improvement is attributable to reduced emission. Particularly, the recent weakening of the Aleutian low could make the tropospheric flow over South Korea more zonal, which can increase the wind speed across the country, consequently reducing the residence time of air pollutants. Hence, we can say that the change in large-scale tropospheric circulation could have contributed to the recent improvements in air quality in South Korea, along with the decreased emission amount due to the government's emissions control measures.

Another interesting research topic would be to investigate the possible cause of the recently weakened Aleutian low. The weakening of the Aleutian low has become evident after 2001 (not shown). Although this is beyond the scope of the present study, it may be valuable to discuss the possible mechanisms in a future study. Various factors may account for the recent changes in the Aleutian low. The Aleutian low is generally linked to a teleconnection pattern that is strongly affected by the variation in sea surface temperature over the Pacific, such as El Niño-Southern Oscillation (ENSO) and the Pacific decadal oscillation (PDO; Wang et al. 2000; Rodionov et al. 2005; Wang et al. 2012). The relationship between ENSO events and the Aleutian low has been known since the mid-1960s (Bjerknes 1966). In particular, the Pacific-North America (PNA) pattern, which is the downstream effect of ENSO, determines both the strength and the central position of the Aleutian low (Wang et al. 2012). A positive (negative) PNA indicates an intensified (weakened) Aleutian 

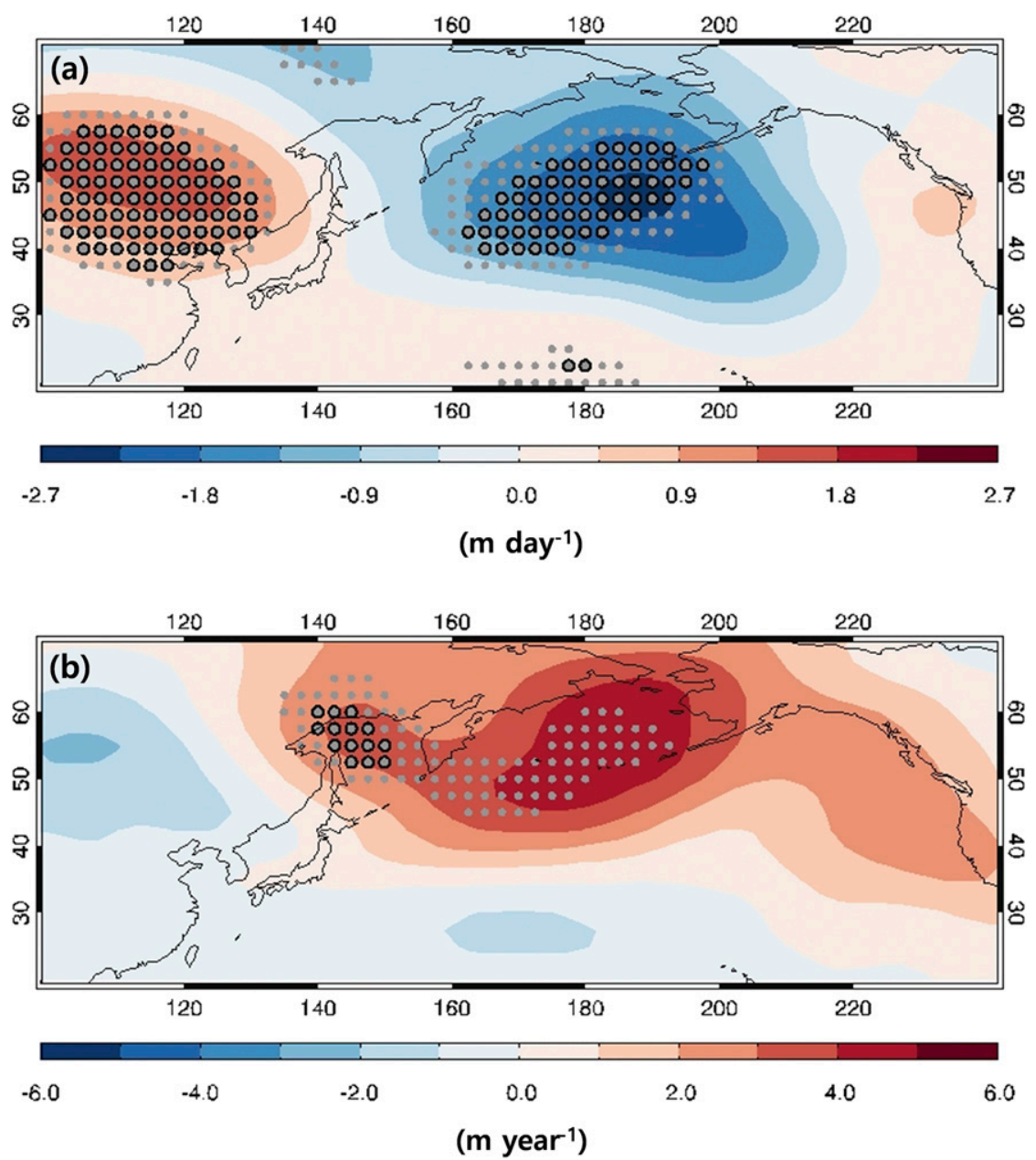

FIG. 5. Regression map of 500-hPa geopotential height against the (a) similar-pattern days and (b) trend of average anomalous geopotential height at $500 \mathrm{hPa}$ during the cold season. Gray and black dots denote the regions significant at the $90 \%$ and $95 \%$ confidence levels based on the Student's $t$ test, respectively.

low (Rodionov et al. 2005). Mantua et al. (1997) suggested that the Aleutian low is significantly correlated with the PDO, with the warm (cold) phase of the PDO corresponding to a strong (weak) Aleutian low. Kao et al. (2016) reported that the Aleutian low affected by the negative PDO phase plays a role in the weakening of the East Asian winter monsoon circulation, which is further related to the changes in air quality in East Asia (Li et al. 2016; Yang et al. 2016). The Arctic Oscillation (AO) also can affect the Aleutian low (Overland et al. 1999; Sun and Wang 2006), with a strong AO potentially resulting in the deepening of the Aleutian low. Based on these previous studies, we examine several indices (i.e., PNA, East Asian winter monsoon, PDO, and AO) to account for the recent changes in the Aleutian low. However, we cannot find a significant relationship between the indices and the change in the Aleutian low.
The PDO is more likely to be a factor than others. In fact, the cold phase of the PDO was under way from 2002/03 to 2013/14 (http://research.jisao.washington.edu/pdo; Fig. S1). However, some strong peaks during the cold seasons of 2001/02, 2009/10, and 2014/15 could not account for the relatively steady reduction of high- $\mathrm{PM}_{10}$ and similar-pattern days (Figs. 1, 4a; Fig. S2). Presumably, the recently weakened Aleutian low cannot be fully explained by one index. It may be a combined effect such as various large-scale variations and/or global warming. More in-depth investigation on the mechanisms of weakened Aleutian low is necessary, which can be a topic for further study.

Acknowledgments. This study was funded by the South Korea Ministry of Environment (MOE) as "Climate Change Correspondence Program." 


\section{REFERENCES}

Ahmed, E., K.-H. Kim, Z.-H. Shon, and S.-K. Song, 2015: Longterm trend of airborne particulate matter in Seoul, Korea from 2004 to 2013. Atmos. Environ., 101, 125-133, https://doi.org/ 10.1016/j.atmosenv.2014.11.024.

Anderson, J. O., J. G. Thundiyil, and A. Stolbach, 2012: Clearing the air: A review of the effects of particulate matter air pollution on human health. J. Med. Toxicol., 8, 166-175, https:// doi.org/10.1007/s13181-011-0203-1.

Baek, S.-O., and Y.-S. Koo, 2008: Critical evaluation of and suggestions for a comprehensive project based on the Special Act on Seoul Metropolitan Air Quality Improvement (in Korean). J. Korean Soc. Atmos. Environ., 24, 108-121, https://doi.org/ 10.5572/KOSAE.2008.24.1.108.

Bjerknes, J., 1966: A possible response of the atmospheric Hadley circulation to equatorial anomalies of ocean temperature. Tellus, 18, 820-829, https://doi.org/10.3402/tellusa.v18i4.9712.

Chang, C. T., and C. J. Tsai, 2003: A model for the relative humidity effect on the readings of the $\mathrm{PM}_{10}$ beta-gauge monitor. J. Aerosol Sci., 34, 1685-1697, https://doi.org/10.1016/ S0021-8502(03)00356-2.

Choi, Y.-S., C.-H. Ho, J. Kim, D.-Y. Gong, and R. J. Park, 2008: The impact of aerosols on the summer rainfall frequency in China. J. Appl. Meteor. Climatol., 47, 1802-1813, https:// doi.org/10.1175/2007JAMC1745.1.

Gao, Y., X. Liu, C. Zhao, and M. Zhang, 2011: Emission controls versus meteorological conditions in determining aerosol concentrations in Beijing during the 2008 Olympic Games. Atmos. Chem. Phys., 11, 12 437-12 451, https://doi.org/ 10.5194/acp-11-12437-2011.

Glotfelty, T., Y. Zhang, P. Karamchandani, and D. G. Streets, 2014: Will the role of intercontinental transport change in a changing climate? Atmos. Chem. Phys., 14, 9379-9402, https:// doi.org/10.5194/acp-14-9379-2014.

Grambsch, A., and Coauthors, 2009: Assessment of the impacts of global change on regional U.S. air quality: A synthesis of climate change impacts on ground-level ozone. EPA Assessment Doc. EPA/600/R-07/094F, 131 pp., https://cfpub.epa.gov/si/si_public_ file_download.cfm?p_download_id=491176\&Lab=NCEA.

Gyeonggi Research Institute, 2011: Points for air quality management plan revision in Seoul metropolitan area (in Korean). Gyeonggi Research Institute, http://www.gri.re.kr.

Harrison, R. M., and J. Yin, 2000: Particulate matter in the atmosphere: Which particle properties are important for its effects on health? Sci. Total Environ., 249, 85-101, https://doi.org/ 10.1016/S0048-9697(99)00513-6.

Hong, Y. C., J. T. Lee, H. Kim, E. H. Ha, J. Schwartz, and D. C. Christiani, 2002: Effects of air pollutants on acute stroke mortality. Environ. Health Perspect., 110, 187-191, https:// doi.org/10.1289/ehp.02110187.

Hyslop, N. P., 2009: Impaired visibility: The air pollution people see. Atmos. Environ., 43, 182-195, https://doi.org/ 10.1016/j.atmosenv.2008.09.067.

Kalnay, E., and Coauthors, 1996: The NCEP/NCAR 40-Year Reanalysis Project. Bull. Amer. Meteor. Soc., 77, 437-471, https:// doi.org/10.1175/1520-0477(1996)077<0437:TNYRP>2.0.CO;2.

Kamal-Chaoui, L., F. Grazi, J. Joo, and M. Plouin, 2011: The implementation of the Korean Green Growth Strategy in urban areas. OECD Regional Development Working Papers Rep., 88 pp., https://doi.org/10.1787/5kg8bf4l4lvg-en.

Kao, P., C. Hung, and H.-H. Hsu, 2016: Decadal variation of the East Asian winter monsoon and Pacific decadal oscillation.
Terr. Atmos. Ocean Sci., 27, 617-624, https://doi.org/10.3319/ TAO.2016.05.29.01.

Kim, D., and Coauthors, 2010: A study on the improvement of emission estimate methods for the air pollutants (in Korean). National Institute of Environmental Research Rep. 2010-99127, 38 pp., http://webbook.me.go.kr/DLi-File/pdf/2011/07/ 5265482.pdf.

Kim, H.-C., and Coauthors, 2017: Recent increase of surface particulate matter concentration in the Seoul metropolitan area, Korea. Sci. Rep., 7, 4710, https://doi.org/10.1038/ s41598-017-05092-8.

Kim, K.-H., and Z.-H. Shon, 2011: Long-term changes in $\mathrm{PM}_{10}$ levels in urban air in relation with air quality control efforts. Atmos. Environ., 45, 3309-3317, https://doi.org/ 10.1016/j.atmosenv.2011.03.033.

— - S. K. Pandey, H. T. Nguyen, S.-Y. Chung, S.-J. Cho, M.-Y. Kim, J.-M. Oh, and Y. Sunwoo, 2010: Long-term behavior of particulate matters at urban roadside and background locations in Seoul, Korea. Transp. Res., 15D, 168-174, https://doi.org/10.1016/j.trd.2009.12.001.

Kim, S., K.-H. Hong, H. Jun, Y.-J. Park, M. Park, and Y. Sunwoo, 2014: Effect of precipitation on air pollutant concentration in Seoul, Korea. Asian J. Atmos. Environ., 8, 202-211, https:// doi.org/10.5572/ajae.2014.8.4.202.

Koo, Y.-S., H.-Y. Yun, H.-Y. Kwon, and S.-H. Yu, 2010: A development of $\mathrm{PM}_{10}$ forecasting system (in Korean). J. Korean Soc. Atmos. Environ., 26, 666-682, https://doi.org/10.5572/ KOSAE.2010.26.6.666.

Lau, K.-M., and Coauthors, 2008: The Joint Aerosol-Monsoon Experiment: A new challenge for monsoon climate research. Bull. Amer. Meteor. Soc., 89, 369-384, https://doi.org/10.1175/ BAMS-89-3-369.

Lee, S., C.-H. Ho, and Y.-S. Choi, 2011: High-PM PM $_{10}$ concentration episodes in Seoul, Korea: Background sources and related meteorological conditions. Atmos. Environ., 45, 7240-7247, https://doi.org/10.1016/j.atmosenv.2011.08.071.

,-- - Y. G. Lee, H.-J. Choi, and C.-K. Song, 2013: Influence of transboundary air pollutants from China on the high- $\mathrm{PM}_{10}$ episode in Seoul, Korea for the period October 16-20, 2008. Atmos. Environ., 77, 430-439, https://doi.org/ 10.1016/j.atmosenv.2013.05.006.

Levy, R. C., S. Mattoo, L. A. Munchak, L. A. Remer, A. M. Sayer, F. Patadia, and N. C. Hsu, 2013: The collection 6 MODIS aerosol products over land and ocean. Atmos. Meas. Tech., 6 , 2989-3034, https://doi.org/10.5194/amt-6-2989-2013.

Li, Q., R. Zhang, and Y. Wang, 2016: Interannual variation of the wintertime fog-haze days across central and eastern China and its relation with East Asian winter monsoon. Int. J. Climatol., 36, 346-354, https://doi.org/10.1002/joc.4350.

Loosmore, G. A., and R. T. Cederwall, 2004: Precipitation scavenging of atmospheric aerosols for emergency response applications: Testing an updated model with new real-time data. Atmos. Environ., 38, 993-1003, https://doi.org/10.1016/ j.atmosenv.2003.10.055.

Mantua, N. J., S. R. Hare, Y. Zhang, J. M. Wallace, and R. C. Francis, 1997: A Pacific interdecadal climate oscillation with impacts on salmon production. Bull. Amer. Meteor. Soc., 78 , 1069-1079, https://doi.org/10.1175/1520-0477(1997)078<1069: APICOW $>2.0 . \mathrm{CO} ; 2$.

Oh, H.-R., C.-H. Ho, J. Kim, D. Chen, S. Lee, Y.-S. Choi, L.-S. Chang, and C.-K. Song, 2015: Long-range transport of air pollutants originating in China: A possible major cause of multi-day high- $\mathrm{PM}_{10}$ episodes during cold season in Seoul, 
Korea. Atmos. Environ., 109, 23-30, https://doi.org/10.1016/ j.atmosenv.2015.03.005.

Overland, J. E., J. M. Adams, and N. A. Bond, 1999: Decadal variability of the Aleutian low and its relation to high-latitude circulation. J. Climate, 12, 1542-1548, https://doi.org/10.1175/ 1520-0442(1999)012<1542:DVOTAL >2.0.CO;2.

Pope, C. A., III, and D. W. Dockery, 2006: Health effects of fine particulate air pollution: Lines that connect. J. Air Waste Manage. Assoc., 56, 709-742, https://doi.org/10.1080/ 10473289.2006.10464485.

Pun, B. K., and C. Seigneur, 1999: Understanding particulate matter formation in the California San Joaquin Valley: Conceptual model and data needs. Atmos. Environ., 33, 48654875, https://doi.org/10.1016/S1352-2310(99)00266-6.

Rodionov, S. N., J. E. Overland, and N. A. Bond, 2005: The Aleutian low and winter climatic conditions in the Bering Sea. Part I: Classification. J. Climate, 18, 160-177, https://doi.org/ 10.1175/JCLI3253.1.

Samoli, E., and Coauthors, 2008: Acute effects of ambient particulate matter on mortality in Europe and North America: Results from the APHENA study. Environ. Health Perspect., 116, 1480-1486, https://doi.org/10.1289/ehp.11345.

Seo, J., J. Y. Kim, D. Youn, J. Y. Lee, H. Kim, Y. B. Lim, Y. Kim, and H. C. Jin, 2017: On the multiday haze in the Asian continental outflow: The important role of synoptic conditions combined with regional and local sources. Atmos. Chem. Phys., 17, 9311-9332, https://doi.org/10.5194/acp-17-9311-2017.

Shin, M.-K., C.-D. Lee, H.-S. Ha, C.-S. Choe, and Y.-H. Kim, 2007: The influence of meteorological factors on $\mathrm{PM}_{10}$ concentration in Incheon (in Korean). J. Korean Soc. Atmos. Environ. 23, 322-331, https://doi.org/10.5572/KOSAE.2007.23.3.322.

Shin, S. E., C. H. Jung, and Y. P. Kim, 2011: Analysis of the measurement difference for the $\mathrm{PM}_{10}$ concentrations between betaray absorption and gravimetric methods at Gosan. Aerosol Air Qual. Res., 11, 846-853, https://doi.org/10.4209/aaqr.2011.04.0041.

Stefan, S., and I. Roman, 2015: Variability of local $\mathrm{PM}_{10}$ mass concentrations in connection with blocking air circulation.
Meteor. Atmos. Phys., 127, 333-343, https://doi.org/10.1007/ s00703-014-0364-y.

Sun, J., and H. Wang, 2006: Relationship between Arctic Oscillation and Pacific decadal oscillation on decadal timescale. Chin. Sci. Bull., 51, 75-79, https://doi.org/10.1007/s11434-004-0221-3.

Titos, G., H. Lyamani, M. Pandolfi, A. Alastuey, and L. AladosArboledas, 2014: Identification of fine $\left(\mathrm{PM}_{1}\right)$ and coarse $\left(\mathrm{PM}_{10-1}\right)$ sources of particulate matter in an urban environment. Atmos. Environ., 89, 593-602, https://doi.org/10.1016/ j.atmosenv.2014.03.001.

Wang, B., R. Wu, and X. Fu, 2000: Pacific-East Asian teleconnection: How does ENSO affect East Asian climate? J. Climate, 13, 1517-1536, https://doi.org/10.1175/1520-0442(2000) $013<1517$ :PEATHD $>2.0$. CO;2.

Wang, P., J. X. Wang, H. Zhi, Y. Wang, and X. Sun, 2012: Circulation indices of the Aleutian low pressure system: Definitions and relationships to climate anomalies in the Northern Hemisphere. Adv. Atmos. Sci., 29, 1111-1118, https://doi.org/ 10.1007/s00376-012-1196-7.

WHO, 2006: Air quality guidelines: Global update 2005. WHO Rep., 484 pp., http://www.who.int/phe/health_topics/outdoorair/ outdoorair_aqg/en.

Yang, Y., H. Liao, and S. Lou, 2016: Increase in winter haze over eastern China in recent decades: Roles of variations in meteorological parameters and anthropogenic emissions. J. Geophys. Res., 121, 13 050-13 065, https://doi.org/10.1002/ 2016 JD025136.

Zhang, L., and Coauthors, 2008: Transpacific transport of ozone pollution and the effect of recent Asian emission increases on air quality in North America: An integrated analysis using satellite, aircraft, ozonesonde, and surface observations. Atmos. Chem. Phys., 8, 6117-6136, https://doi.org/10.5194/ acp-8-6117-2008.

Zhang, X., and Coauthors, 2009: Changes of atmospheric composition and optical properties over Beijing-2008 Olympic Monitoring Campaign. Bull. Amer. Meteor. Soc., 90, 16331651, https://doi.org/10.1175/2009BAMS2804.1. 